\title{
Credit for the Poor: The Experience of Rural Development Scheme of Islami Bank Bangladesh Ltd.
}

\author{
Mohammad Main Uddin
}

\begin{abstract}
Islami Bank Bangladesh Limited was founded with the major objective of establishing Islamic economy for balanced economic growth by ensuring reduction of rural-urban disparity and equitable distribution of income. In view of the above, Branches of the Bank have been encouraged to invest their deposits in their respective areas and in particular for the economic upliftment of the rural people. Accordingly, a scheme in the name and style of 'Rural Development Scheme' has been introduced to cater to the investment needs of the agriculture and rural sector to create opportunity for generation of employment and raising income of the rural people with a view to alleviate poverty.
\end{abstract}

Key words : Islami Bank Bangladesh Ltd (IBBL), Rural Development Scheme (RDS), credit, investment, poor

\section{Introduction}

Bangladesh with its $40 \%$ people living below poverty line and $18 \%$ living in absolute poverty is suffering from acute rural-urban economic disparity coupled with illiteracy, lack of proper health and sanitation facilities. The country's economy is basically an agrarian one with vast majority living in rural areas. The agriculture sector is unable to provide any further scope for employment resulting in influx of rural population towards urban areas. Rural areas are characterised by stagnant agriculture and scanty industries. Underemployment and unemployment is a regular phenomenon particularly in rural areas. The vast human resources have remained unutilised due to lack of education, proper training and concerted efforts to help grow the rural economy. This result in uneven distribution of income which causes serious set back in balanced geographical growth as well as growth of GDP.

The Fifth Five Year Plan (FFYP) of the government of Bangladesh includes poverty alleviation as one of its Major objectives. The plan wants to achieve these objectives through accelerating economic growth during the plan period to bring about a noticeable improvement in the standard of living of the citizen of Bangladesh by rising their level of income and ensuring adequate supply of basic needs. Micro-credit has come to light as the latest alternative approach to alleviating rural poverty. The principle of group-based micro credit program initiated by Nobel laureate professor Dr. Yunus in 1976 has been acknowledged as 
a model of rural poverty alleviation. It has created a nation of high expectation since early 90's as a powerful instrument of creating freedom and self-employment opportunities for the distressed rural poor. At present, micro-credit programs are being run in the more than seventy countries of the world for the eradication of massive poverty from the countries.

Islam treats poverty as a social as well as ideological evil. It is a social evil because it degrades societal status of the vicegerents of Allah, gives birth to many social problem and out the poor nations as a disadvantaged position in the world society of human race. Islam dislike poverty and hence it is the obligation of the rich to help the needy for its eradiation so much, so that the neglect of this obligation resembles denial of Islam itself.

In such a situation Islami Bank Bangladesh limited (IBBL) started a program named "Rural Development Scheme (RDS)" to scene as group based micro credit in 1995 with very high promise to eliminate rural poverty. Although some of the commercial and specialized banks and a few NGO's had been providing small amount of credit to the rural poor before the establishment of the RDS. The micro credit programs have tremendously expanded in Bangladesh in rural development. Up to September 2007, IBBL has disbursed a total Tk.12840.02 million among 4,93,110 households covering 9388 villages of the country. But in spite of the huge coverage of Rural Development Scheme in the last one and quarter decades, the socio-economic and socio political progress of the rural poor including women empowerment have not been significantly achieved. So, there might have been some problems either in the operational system of IBBL or in the investment utilization process of the clients, which should be examined critically. In this study an attempt has been made to analyze the socio economic impact of the RDS investment to change the life style of its members.

\section{Rural Financing under Islamic Framework}

Rural development initiatives under the Islamic framework in Bangladesh are of recent origin. At present 62 Islamic NGOs are working in Bangladesh. Ten organizations are working with the credit only approach whereas 35 organizations are operating on credit plus principle having program components like non-formal education, health and sanitation along with micro investments. Three organizations are doing relief and rehabilitation, four are engaged in education, cultural and research activities and two are involved in preaching. Organizations with either the 'credit only' or 'credit plus' approach, follow the target grouping strategy in their investment financing and apply 'Bai-Muajjal' or deferred payment as a primary financing technique. 


\section{Objectives of the Study}

The main objective of the study is to appraise the existing investment under "Rural Development Scheme (RDS)" of Islami Bank Bangladesh Ltd. The specific objectives of the study are as follows: -

a) To answer the impact of Rural Development Scheme (RDS) of IBBL on the socioeconomic development of its member/borrowers.

b) To examine the role of RDS in rural development and poverty alleviation.

c) To aims the impact of RDS investment on the different indication of women empowerment.

\section{Methodology of the Study}

The present study makes an attempt to apply the method of documentary analysis and survey method. Documentary analysis is an attempt to find out what has happened in the course of time and to correlate the events, within the limits of available materials on the hand and of the researcher's intelligence and understanding on the other, in the meaningful sequence. In order to examine the impacts of the RDS investment of IBBL on the vulnerable rural poor of Bangladesh, the present study exclusively user's empirical and indicative methods by compiling the data from relevant documents published so far. Also conducted surveys, personal interview, and distribution of questionnaires and observation.

\section{Selection of the Study Area}

Islami Bank Bangladesh limited, new market branch, Rajshahi has been purposively selected as because that branch has Rural Development Scheme (RDS). It is presumed that those areas would represent the whole of Bangladesh, because these areas \& members are selected randomly $\&$ it is also argued that people who live in rural areas follows same culture, food habit, norms, style. Moreover they also live in under same economic condition and their family income, occupation, expenditure and standard of living, etc are morally the same. Islami Bank Bangladesh Limited, Rajshahi Branch started its RDS activities in 1997 (later RDS section was shifted to New market Branch) with only two female centers having 90 members only. In 1997, it disbursed only TK 2, 14,000 under RDS.

\section{Selection of Sample}

50 members randomly selected in the study area and getting responses from them. Data were collected through interviews with the selected RDS members covering information on socio economic backgrounds of the member householders, their credit history, income, expenditure pattern, investment and their own view about the RDS. The collected raw data were processed for preparation of statistical tables, charts, and graphs. Subsequently, 
necessary statistical tables, charts, diagrams, etc have been prepared to facilitate analysis and interpretation of collected information.

\section{Limitation of the Study}

This study is not free from limitation. The poor client did not maintain proper accounts and as such they had to provide information from their memories. Moreover, the respondents were reluctant in providing information, about investment, dues, income, expenditure, savings and their relationship with the bank employees. $92 \%$ of the total members are female (Sep. 2007) at the respondents among RDS members were women. In fact, no survey of male members of RDS has been carried out. Therefore, a comparative study of the female numbers performance with their male counterparts could not be high lighted. This study does not focus on the management related aspects of RDS and its impact on the members. Due to time constraints, resources, facilities the study could not cover a large sample. However, all attempts have been made to collect the required information as accurately as possible.

\section{Findings of the Study}

\section{Age Structure of the Respondent}

Age of the members referred to the period of time from his/her birth up to the time of interview. The age was measured in terms of years. Age of a person is a crucial determinant of the ability to perform a job. A young person can better apply his or her eagerness, dedication, consciousness and motivation towards achieving a target successfully. So age structure of the members is very important in the context of their ability to get out of poverty.

Table 01 : Age of the respondent

\begin{tabular}{|c|c|c|}
\hline Age Groups (Years) & No. of respondents & In Percentage \\
\hline $20-30$ & 6 & $12 \%$ \\
\hline $31-40$ & 27 & $54 \%$ \\
\hline More than 40 & 17 & $34 \%$ \\
\hline Total & 50 & 100 \\
\hline
\end{tabular}

Source: Field Survey 2008

Table 01 show that the age group 31-40 as 54 percent with high percentage of entry. Middle year age group (31-40) persons were very much interested to get investment.34 percent respondent's age group was more than 40 and it implies that at that age they did not get financial support from other, for this reason they got investment from RDS. So the IBBL is not selecting the most potential youth group as investment holders. 


\section{Level of Education}

Education is a very important factor for an individual to achieve better alternatives available in rural areas in which he/ she can invest the fund profitably and efficiently. Education is the foundation in which human qualities are built. It is the key variable to develop group conciseness and community awareness of the target group members. The education level was determined in terms of the highest class passed by him $/$ her.

Table 02 : Level of education of the RDS members

\begin{tabular}{|l|c|c|}
\hline Level of education & No. of respondents & In Percentage \\
\hline Illiterate & 0 & $0 \%$ \\
\hline Can sign only & 9 & $18 \%$ \\
\hline Primary level & 31 & $62 \%$ \\
\hline Junior high & 7 & $14 \%$ \\
\hline Secondary \& Above & 3 & $6 \%$ \\
\hline Total & 50 & 100 \\
\hline
\end{tabular}

Source: Field Survey 2008

From the table 02 it is clear that there was no illiterate person. Table also shows that 62 percent members completed primary level of education, 14 percent-completed junior high level and 6 percent responding member's attained secondary school and above. It is important to note that the percentage of primary education was high and $100 \%$ members know to put signature.

\section{Learned to put Signature}

It is an important criterion to get RDS investment. In order to be a member he/she must learn to put signature. It is also said that education is called the backbone of a nation. An attempt was made to know about education status and asked them "Did you learn to put signature only get RDS investment?"

Table 04 : Learned to put signature

\begin{tabular}{|l|r|r|}
\hline \multicolumn{1}{|c|}{ Factors } & No. of respondents & \multicolumn{1}{c|}{ In Percentage } \\
\hline Yes & 7 & $14 \%$ \\
\hline No & 43 & $86 \%$ \\
\hline Total & 50 & 100 \\
\hline
\end{tabular}

Source: Field Survey 2008

Table 04 indicates that 86 percent of the total members have learnt to put signature before joining RDS but 14 percent the respondent were not able to make any signature clearly before joining RDS. However after entering into the RDS they have learnt how to 
sign their names clearly. So it can be said that it is great achievement of RDS to lessen the illiteracy rate of the rural poor in the country.

\section{Marital Condition of the Members}

Marital status is an important variable to form a group interaction. It has been classified in connection with married, unmarried and widow.

Table 05 : Marital condition of the members

\begin{tabular}{|l|c|c|}
\hline \multicolumn{1}{|c|}{ Categories } & No. of respondents & In percentage \\
\hline Married & 48 & $96 \%$ \\
\hline Unmarried & 0 & $0 \%$ \\
\hline Widow Total & 2 & $4 \%$ \\
\hline \multicolumn{2}{|c|}{ Tow } \\
\hline
\end{tabular}

Source: Field Survey 2008

Table 05 demonstrates the martial condition of the members. No unmarried person was found to have joined the RDS. In respect of marital condition, the table expose that $96 \%$ of the members are married and $4 \%$ are widow. It is also clear that unmarried women are restricted by social customs to go outside and undertaken public activities freely.

\section{Number of Family Members}

The family size has diversified effects on the socio economic circumstances of the members. The results in table 06 indicate the number of the family members.

Table 06 : Number of the family members

\begin{tabular}{|c|c|c|}
\hline Family size & No. of Respondents & $\mathbf{\%}$ \\
\hline $1-3$ & 26 & 52 \\
\hline $4-6$ & 20 & 40 \\
\hline More than 6 & 4 & 8 \\
\hline Total & 50 & 100 \\
\hline
\end{tabular}

\section{Source: Field Survey 2008}

The table 06 shows that after joining RDS 58\% of the respondents have family members ranging from 1 to $3.36 \%$ respondents have family size between 4 to 6 and 7 and above family members were noticed in 6\%. On the other hand before joining project $52 \%$ of the respondents had family members ranging from 1 to $3.40 \%$ of the respondents had family size ranging from 4 to 6 and $8 \%$ of the respondents have family size 7 and above.

\section{Occupation of the Member}

For the successful utilization of investment, the members need to engaged in some 
economic activities. IBBL claims that progress are empowering poor members though creation of diversified self-employment opportunities for them. The table 07 indicates the own occupation of the members before and after joining RDS.

Table 07 : Members' occupation before and after joining RDS

\begin{tabular}{|l|r|r|r|r|}
\hline \multirow{2}{*}{ Occupation } & \multicolumn{3}{|c|}{ Before Joining RDS } & \multicolumn{2}{c|}{ After Joining RDS } \\
\cline { 2 - 6 } & No. of Respondents & \multicolumn{1}{c|}{$\%$} & No. of Respondents & $\%$ \\
\hline Housewife & 35 & 70 & 30 & 60 \\
\hline Self employed & 3 & 6 & 7 & 14 \\
\hline Employed & 4 & 8 & 1 & 2 \\
\hline Housewife and self employed & 8 & 16 & 12 & 24 \\
\hline Total & 50 & 100 & 50 & 100 \\
\hline
\end{tabular}

Source: Field Survey2008

The above table reveals that $70 \%$ of the respondents were employed as housewives before joining RDS. The next comes self-employed which accounts for $6 \%$ followed by employed $8 \%$ and housewife and self employed also $16 \%$. However, after RDS financing the occupational structure has undergone significant changes. Now housewife and self employed which account for $60 \%$. Followed by self-employed $14 \%$, employed $2 \%$ of the total members and $60 \%$ are exclusively engaged in household affairs. They are not contributors to their family income. From the statistics shown in the above table, it can be said that impact of RDS investment are significantly positive for self-employment.

\section{Spouse Occupation}

As my entire sample members were female and married that's why here spouse means their husbands.

Table 08 : Spouse's occupation before and after joining RDS

\begin{tabular}{|l|r|r|r|r|}
\hline \multirow{2}{*}{ Occupations } & \multicolumn{2}{|c|}{ Before Joining RDS } & \multicolumn{2}{c|}{ After Joining RDS } \\
\cline { 2 - 6 } & No. of Respondents & \multicolumn{1}{c|}{$\%$} & No. of Respondents & \multicolumn{1}{c|}{$\%$} \\
\hline Day Labor & 5 & 10 & 3 & 6 \\
\hline Small Business/Grocery & 25 & 50 & 33 & 66 \\
\hline Agriculture & 7 & 14 & 4 & 8 \\
\hline Transportation & 8 & 16 & 7 & 14 \\
\hline Service & 5 & 10 & 3 & 6 \\
\hline Housewife & 0 & 0 & 0 & 0 \\
\hline Total & 50 & 100 & 50 & 100 \\
\hline
\end{tabular}

Source: Field Survey2008 
From the table 08 it is shown that $10 \%$ of the respondents' husbands were day labors, $50 \%$ engaged in small businesses $14 \%$ in agriculture, $16 \%$ were Van, Rickshaw pullers, $10 \%$ were service holders. This position was before Joining RDS. However, after in involvement in RDS, it is focused from the data showed in the table that the investment of the day labor has been declined from $10 \%$ to $6 \%$, agriculture has been declined from $14 \%$ to $8 \%$ transportation services decreased from $16 \%$ to $14 \%$.On the other hand, small business has been increased from $50 \%$ to $60 \%$. The above information provides an indication that the investment is creating a positive on occupations of the member's spouse. It is seen from the field survey that they took investment for helping their husband's business.

\section{Utilization of Investment}

Invested money must be utilized in any legal income generating activities. RDS provides financial assistance for various works. It is known that investment was sanctioned for more than eight different sectors. These sectors are grouped under two broad categories, which are farm and off farm activities. The following table 09 states that share of different sectors of investment are used by the members in the sample area.

Table 09 : Utilization of investment money by the members

\begin{tabular}{|l|c|c|}
\hline \multicolumn{1}{|c|}{ Activities } & No. of respondents & In percentage \\
\hline Farming & 2 & $4 \%$ \\
\hline Manufacturing and processing & 2 & $4 \%$ \\
\hline Service & 12 & $24 \%$ \\
\hline Trading & 8 & $16 \%$ \\
\hline Shops & 16 & $32 \%$ \\
\hline Padding & 1 & $2 \%$ \\
\hline Plantation & 3 & $6 \%$ \\
\hline Livestock & 6 & $12 \%$ \\
\hline Total & 50 & 100 \\
\hline
\end{tabular}

Source: Field Survey 2008

Table 09 shows that before joining RDS 14\% of respondents were living kacha (clay base) house and after joining RDS this percent were reduced by $8 \%$ semi pacca were increased from $76 \%$ to $82 \%$, and pacca (brick built) were also increased from $10 \%$ to $12 \%$. From this table it can be said that RDS investment helps to raise there level of income as well as condition of shelter life. 
Food

People living in Bangladesh on one or more cereals such as rice, white and maize often suffer from neutron on in sufficient calorie intake. It is usually claimed that RDS has been working in Bangladesh to improve the living standard of the rural poor people. In view of this assertion an attempt was made to know the fooding profile of RDSs members.

Table 10 : Fooding standard before and after using investment of RDS investment

\begin{tabular}{|c|c|c|c|c|}
\hline \multirow{2}{*}{ Fooding } & \multicolumn{2}{|c|}{ Before Joining RDS } & \multicolumn{2}{c|}{ After Joining RDS } \\
\cline { 2 - 5 } & No. of Respondents & $\%$ & No. of Respondents & $\%$ \\
\hline Normal Food & 22 & 44 & 19 & 38 \\
\hline Medium Food & 24 & 48 & 25 & 50 \\
\hline Rich Food & 4 & 8 & 6 & 12 \\
\hline Total & 50 & 100 & 50 & 100 \\
\hline
\end{tabular}

Source: Field Survey2008

Table 10 shows that $44 \%$ respondents would eat normal food three times daily. $48 \%$ of the respondent would eat medium food three times daily and 8 percent respondents consumed rich food. In the contrary after taking investment of RDS it has benefited change i.e. only $38 \%$ respondents consumed normal food and changes the figure from $44 \%$ to $38 \%$. $50 \%$ respondents consumed medium food. It has changed from $48 \%$ to $50.5 \%$ and from 8 percent to $12 \%$ respondents changed their food menu into rich food after taking investment of RDS. It is remarked that RDS has brought tremendous change of rural economic of the village poor people of the country.

\section{Clothing}

The second most basic need of human being is clothing, inadequacy of it reflects poverty.

Table 11 : Clothing standard before and after joining RDS

\begin{tabular}{|l|c|c|c|c|}
\hline \multirow{2}{*}{ Yearly Expenditure(Tk.) } & \multicolumn{2}{|c|}{ Before Joining RDS } & \multicolumn{2}{c|}{ After Joining RDS } \\
\cline { 2 - 5 } & No. of Respondents & $\%$ & No. of Respondents & $\%$ \\
\hline $0-2000$ & 17 & 34 & 5 & 10 \\
\hline $2001-4000$ & 28 & 56 & 38 & 76 \\
\hline More than 4000 & 5 & 10 & 7 & 14 \\
\hline Total & 50 & 100 & 50 & 100 \\
\hline
\end{tabular}

Source: Field Survey 2008

The above table and graph show that before joining RDS, 34\%,56\%,10\% members' expenditure for clothing were within Tk 0-2000,tk2001-4000,more than 4000 respectively whereas after joining RDS 75\% members' expenditures for clothing was within 2001-4000. It indicates that members' expenditure for clothing is gradually increasing over time after joining RDS. 


\section{Health and Medical facilities}

Health is one of the basic needs, which reflects the quality of life. Health for all is vital for making basic needs universal.

Table 12 : Health and medical facilities before and after joining RDS

\begin{tabular}{|c|c|c|c|c|}
\hline \multirow{2}{*}{ Nature } & \multicolumn{2}{|c|}{ Before Joining RDS } & \multicolumn{2}{c|}{ After Joining RDS } \\
\cline { 2 - 5 } & No. of Respondents & $\%$ & No. of Respondents & $\%$ \\
\hline Fakir/Kabiraj & 11 & 22 & 2 & 4 \\
\hline Quack doctor/Homeopathic & 29 & 58 & 33 & 66 \\
\hline MBBS & 10 & 20 & 15 & 30 \\
\hline Total & 50 & 100 & 50 & 100 \\
\hline
\end{tabular}

Source: Field Survey 2008

In the study area, the table shows that before joining RDS only $20 \%$ house holds has access to modern health care services but the percentage was increased to $30 \%$ after joining RDS. The large number of members $58 \%$ has access Quack doctor/homeopathic before joining RDS which has been increased to $66 \%$ after joining RDS.From the above data it can be said that RDS has been trying to improve to take health care services.

\section{Sources of Drinking Water}

Safe water is considered as component of basic human need, because they have positive implication. Beside the investment activities, successful members, so far, have been provided with 5525 tube-wells at a cost of Tk 10.66 million on Quard-e-Hasana(profit free investment) basis as a part of health program of the scheme. So, attempt was made to know the sources of drinking water of the members before and after the use of RDS investment.

Table 13 : Sources of Drinking Water Before and After Joining RDS

\begin{tabular}{|c|c|c|c|c|}
\hline \multirow{2}{*}{ Sources of drinking water } & \multicolumn{2}{|c|}{ Before Joining RDS } & \multicolumn{2}{c|}{ After Joining RDS } \\
\cline { 2 - 5 } & No. of Respondents & $\%$ & No. of Respondents & $\%$ \\
\hline Public tube-well & 8 & 16 & 4 & 8 \\
\hline Personal tube-well & 39 & 78 & 45 & 90 \\
\hline Pond Water/ Other Sources & 3 & 6 & 1 & 2 \\
\hline Total & 50 & 100 & 50 & 100 \\
\hline
\end{tabular}

Source: Field Survey 2008

Table shows that out of total respondents $78 \%$ members used own tube-well and $16 \%, 6 \%$ members used public tube-well, other sources respectively before joining RDS. This position has been changed through RDS operation. After the use of RDS the users of own tube well water in creased from $78 \%$ to $90 \%$ and the percentage of public tube well water uses decreased from $16 \%$ to $8 \%$ and the use of pond/other sources water by the respondents 
also declined from $6 \%$ to $2 \%$. This bears the imprint of qualitative sign development in the living standard of respondents. From the analysis it is clear that RDS investment and IBF provide proper financial assistance to improve the source of drinking water.

\section{Nature of Latrine}

Persons having awareness and sense for health and diseases consider that sanitary latrine were essential part to ensure hygienic environment. Sanitary latrine means scientific latrine. Up to 31.12.2006, IBBL, beside the investment activities, successful members, so far, have been provided with 3235sanaitary latrines at a cost of Tk 2.99 million on Quarde-Hasana (profit free investment) basis as a part of sanitation program of the scheme.

Table 14 : Nature of latrine used by the members

\begin{tabular}{|c|c|c|c|c|}
\hline \multirow{2}{*}{ Nature of latrine used } & \multicolumn{2}{|c|}{ Before Joining RDS } & \multicolumn{2}{c|}{ After Joining RDS } \\
\cline { 2 - 5 } & No. of Respondents & $\%$ & No. of Respondents & $\%$ \\
\hline Sanitary latrine & 42 & 84 & 47 & 94 \\
\hline Unsanitary latrine & 8 & 16 & 3 & 6 \\
\hline Total & 50 & 100 & 50 & 100 \\
\hline
\end{tabular}

Source: Field Survey 2008

The above table shows that People used sanitary latrine when their health consciousness increase along with an improvement in their financial position. after getting investment from RDS the users of unscientific latrine were reduced from $16 \%$ to $6 \%$. On the other hand users of scientific latrine were increased from $84 \%$ to $94 \%$. The analysis provides a richer and more complex picture of the linkage between RDS and the sanitary latrine use while also providing evidence of the influence of socio-economic factor on the outcome.

\section{Furniture Owned by the Respondent Household}

The quantitative and qualitative amount of furniture owned by the household is another indication of the socio economic progress of the members.

Table 15 : Value of furniture

\begin{tabular}{|l|c|c|c|c|}
\hline \multirow{2}{*}{ Amount } & \multicolumn{2}{|c|}{ Before Joining RDS } & \multicolumn{2}{c|}{ After Joining RDS } \\
\cline { 2 - 5 } & No. of Respondents & $\%$ & No. of Respondents & $\%$ \\
\hline Up to 10000 & 15 & 30 & 13 & 26 \\
\hline $10001-20000$ & 30 & 60 & 31 & 62 \\
\hline 20000 and above & 5 & 10 & 6 & 12 \\
\hline Total & 50 & 100 & 50 & 100 \\
\hline
\end{tabular}

Source: Field Survey 2008 
It is clear from the above table that the approximate monetary value of furniture owned by the selected households before $\&$ after joining RDS is almost the same

\section{Homestead}

Table 16 : Homestead before and after using RDS

\begin{tabular}{|c|c|c|c|c|}
\hline \multirow{2}{*}{ Land (Decimals) } & \multicolumn{2}{|c|}{ Before } & \multicolumn{2}{c|}{ After } \\
\cline { 2 - 5 } & No. of Respondents & $\%$ & No. of Respondents & $\%$ \\
\hline Nil & 7 & 14 & 3 & 6 \\
\hline Up to 5 & 21 & 42 & 17 & 34 \\
\hline $5-8$ & 12 & 24 & 16 & 32 \\
\hline $9-15$ & 7 & 14 & 9 & 18 \\
\hline 16 - Above & 3 & 6 & 5 & 10 \\
\hline Total & 50 & 100 & 50 & 100 \\
\hline Average & 4.8 decimals & 5.2 decimals \\
\hline
\end{tabular}

Source: Field Survey 2008

Table 16 shows that before using RDS 42 percent members had up to 5 decimals homestead, 24 percent had between 5 to 8 decimals, 14 percent 9 to 15 decimals, 14 percent respondents were completely landless i.e. they had no any homestead and only 6 percent respondents possessed more than 16 decimals homestead. It has been found that this position has changed after joining RDS. It was observed that the percentage of respondents holding homestead up to 15 decimals declined $70 \%$ to $52 \%$. The percentage of respondents holding homestead from 5 to 8 decimals increased from 24 to $32 \%$, from 9 to 15 decimals increased from 14 to 18 percent and from 16 decimals and above increased from $6 \%$ to $10 \%$. It is also reveled that while $14 \%$ of the respondents had no homestead before joining RDS, after joining RDS and using investments this percentage declined from 14 to 6 percent only. It can be remarked that the financial conditions of the respondents showed a marked improvement due to increment of income of the entrepreneurs using RDS investments.

Cultivable Land

Land ownership is the more useful factor as a discriminator of a rural poor economic status than any other socio-economic factors.

Table 17 : Land-wise distribution of the respondents

\begin{tabular}{|l|c|c|c|c|}
\hline \multirow{2}{*}{ Land (Decimals) } & \multicolumn{2}{|c|}{ Before joining RDS } & \multicolumn{2}{c|}{ After joining RDS } \\
\cline { 2 - 5 } & No. of Respondents & $\%$ & No. of Respondents & $\%$ \\
\hline No. Land (Decimals) & 16 & 32 & 11 & 22 \\
\hline Up to 15 & 21 & 42 & 13 & 26 \\
\hline $16-33$ & 5 & 10 & 10 & 20 \\
\hline
\end{tabular}




\begin{tabular}{|l|c|c|c|c|}
\hline $34-50$ & 6 & 12 & 11 & 22 \\
\hline 51 and more & 2 & 4 & 5 & 10 \\
\hline Total & 50 & 100 & 50 & 100 \\
\hline
\end{tabular}

Source: Field Survey 2008

It can seen from the table 5.30 that 32 percent of the respondents had no cultivable land, 42 percent possessed land up to 15 decimals, 10 percent had 16 to 33 decimals, 12 percent possessed 34 to 50 decimals and 4 percent respondents had more than 50 decimals of cultivable land. This was the position of the respondents before using investments from RDS. It has been found that this position has changed after using investment by the respondents. The analysis of data reveals that 22 percent respondents have up to 15 decimals cultivable land and 10 percent respondents were able to possess more than 50 decimals cultivable land. On the other land, the number of cultivable landless respondents has decreased from 33 to 22 percent. It is true that some of the surveyed entrepreneurs were able to purchase cultivable land from the financial gain derived by using RDS investments.

\section{Annual Expenditure}

Table 18 : Annual expenditure of the members

\begin{tabular}{|l|c|c|c|c|}
\hline \multirow{2}{*}{ Yearly expenditure (Tk.) } & \multicolumn{2}{|c|}{ Before joining RDS } & \multicolumn{2}{c|}{ After joining RDS } \\
\cline { 2 - 5 } & No. of Respondents & $\%$ & No. of Respondents & $\%$ \\
\hline Up to 20000 & 3 & 6 & 2 & 4 \\
\hline $20001-40000$ & 29 & 58 & 21 & 42 \\
\hline $40001-60000$ & 11 & 22 & 15 & 30 \\
\hline $60001-80000$ & 6 & 12 & 9 & 18 \\
\hline 80001 and above & 1 & 2 & 3 & 6 \\
\hline Total & 50 & 100 & 50 & 100 \\
\hline
\end{tabular}

Source: Field Survey 2008

This was the position of the respondents before the acceptance RDS. It has been seen that this position has changed after the use of RDS by the members. Subsequently, it was observed that the percentage of the respondents having expenses 40001 to 60000 per annum increased from $22 \%$ to $30 \%$. On the other hand, the percentage of members who expend yearly more than Tk. 60000 increased from $12 \%$ to $18 \%$. It indicates that the respondents ` purchasing power has increased enormously.

\section{Conclusion}

RDS has large positive impact, which is observed in the case of food intake, housing, education, clothing, taking medical treatment, use of toilet, use of clear pure water, income, 
expenditure and as such economic, socio-economic, health and physiochemical environment. It is observed from the study that RDS helps to improve member's education level. Sanitary facilities enjoyed by RDS members were better than before joining RDS. The income levels have gone up of all members after joining RDS. This has led to higher food security for the poor. The higher level of income has again been translated into higher expenditure for food items and other goods \& services. As time passes RDS members tend to consume good food and this leads to higher intake of nutrients. It has been found that the per capita expenditure on health and education has improved dramatically amongst RDS member's science its intervention. It is also seen as a critical input for small-scale enterprises. One of the most important changes that have taken place in RDS program households are the creation of employment opportunities, particularly for women. Introduction of housing loans and the loans for such things as latrine, education, tube wells and others would definitely attract the general people to come within the umbrella of the RDS.

\section{References}

Ahmad, K. (1992). Economic Development in an Islamic Framework. London: The Islamic Foundation.

Ahmed, Ausaf (1995). "The Evolution of Islamic Banking”. In Encyclopedia of Islamic Banking, London: Institute of Islamic Banking and Insurance.

Ali, M and Sarkar, A. A. (1995). "Islamic Banking: Principles and Operational Methodology". Thoughts on Economics, Vol. 5 No. 3 \& 4. July-December 1995. Dhaka: Islamic Economics Research Bureau.

Hamid, M. A. and Rahman, S.M.H. (2001). Role of Islamic Bank in the Development of Small Entrepreneurs: An Empirical Investigation, IBTRA, IBBL, Dhaka, Bangladesh.

Hossain,M (1984)"Credit for the poor, The Experience of Grameen Bank in Bangladesh,” BIDS, Dhka. IBBL Annual Report- 2006

Islami Bank Polli Unnoyon Barta” (July-Sept 2007).

Manual of RDS, Dhaka, IBBL

Quddus, M.A (1993).” Rural Development in Bangladesh Strategies and Experiences”, BARD, Comilla . Rural Development Scheme (2006), Dhaka; IBBL

www.islamibankbd.com

Yunus, M. (1986), Grameen Bank, A Bank for the Poor, Dkaha,Grameen Bank Yunus, M. (1992), Steps Needed to be taken for Poverty alleviation, Dhaka, Grameen Bank Yunus, M. (1995), Grameen Bank, As I see It, Dhaka, Grameen Bank 